\title{
Interrelationship Between Microvibration and Autonomic Nervous and Endocrine Environment of Menstrual Disorder
}

\author{
Tetsuya GOTO \\ Department of Obstetrics and Gynecology, Faculty of Medicine, Kyushu University, \\ Fukuoka, Japan (Director : Professor Ichiro Taki, M.D.)
}

A constant and invisible vibration on the body surface of the warm-blooded animals was found and named "microvibration", MV by Rohracher in 1946. A number of reports by him and others seem to give evidences that MV is closely related to the activity of the hypothalamus. The hypothalamus has been known to form an essential control center of the autonomic nervous system and give a significant effect on the endocrine function in accordance with hypophysis. Consequently, there might be a functional interrelationship between MV and autonomic nervous and endocrine function, in a sense that MV might indicate a general state of autonomic and endocrine environment, both of which are integrated by the hypothalamus.

MV was recorded for 15 minutes by means of a specially made pick-up. Components of the MV, recorded by applying the pick-up on the thenar eminence of women with normal menstrual cycle and menstrual disorder were analysed. Based on this frequency analysis, $\mathrm{MV}$ could be conveniently classified into five main types, i.e., $\theta, \alpha \mathrm{S}, \alpha \mathrm{F}, \beta$ and $\mathrm{L}$ type in regard to the components which dominated.

Of women with normal menstrual cycles, difference in MV pattern and ratio of energies of $\beta$ and $\theta, \mathrm{E}(\beta) / \mathrm{E}(\theta)$, at six successive phases were investigated. Slow components, $\theta$ and slow $\alpha$ increased and $\alpha \mathrm{s}$, a subtype of $\alpha \mathrm{S}$ was dominant in preovulatory, ovulatory (except for the day following that of ovulation) and premenstrual phases. Making an apparent contrast to this, the MV on the day following that of ovulation and in the postovulatory phase was constituted of increased fast components, fast $\alpha$ and $\beta$, and $\alpha \mathrm{f}$, a subtype of $\alpha \mathrm{F}$ was dominant. In addition, it was observed that the $95 \%$ of $\mathrm{MV}$ of women with normal menstrual cycle was made by almost equal amounts of $\alpha$ s and $\alpha$ fype. Consequently, these two types were thought to be normal and others abnormal. The frequency of abnormal MV was high in women with menstrual disorder.

Of women with menstrual disorder, diencephalohypophysis-adrenocortical function was evaluated by the estimation of urinary 17-OHCS and 17-KS, rapid AGTH test, vasopressin test and SU-4885 test, diencephalohypophysis-ovarian function by the estimation of urinary FSH and estrogen, and sympathetic nerve-adrenomedullar function by the estimation of urinary catecholamine. Interrelationship between $\mathrm{MV}$ and thusly evaluated endocrine and autonomic nervous conditions was investigated.

Urinary 17-OHCS and 17-KS levels were higher in women who showed $\alpha \mathrm{F}$ type of $\mathrm{MV}$ than the $\alpha \mathrm{S}$ type women. The response of plasma free 11-OHCS to rapid ACTH 
test was higher in the $\alpha \mathrm{F}$ type than the $\alpha \mathrm{S}$ type. These results seemed to suggest that the adrenocortical activity of the $\alpha \mathrm{F}$ type was relatively high as compared with the $\alpha \mathrm{S}$ type, because relatively high secretion of endogenous ACTH in the $\alpha \mathrm{F}$ type could be suspected. There observed such a tendency that the responses of both vasopressin and SU-4885 test were lower in the $\alpha \mathrm{F}$ type than the $\alpha \mathrm{S}$ type. This might indicate a decrease of ACTH storage in hypophysis due to higher secretion of endogenous ACTH in the $\alpha \mathrm{F}$ type than the $\alpha \mathrm{S}$ type.

There was no distinct interrelationship between MV and urinary estrogen level, though urinary FSH level of the $\alpha \mathrm{S}$ type was significantly higher than the $\alpha \mathrm{F}$ type.

Urinary catecholamine level was higher in the $\alpha \mathrm{S}$ type than the $\alpha \mathrm{F}$ type. From this result, it was thought that women who showed $\alpha \mathrm{S}$ type of MV might be more sympathicotonic than the $\alpha \mathrm{F}$ type.

The results are summarized as follows:

1) The slow $\alpha$ dominant $\mathrm{MV}$ ( $\alpha \mathrm{S}$ type) is interpreted as indicating a sympathicotonic state with relatively high FSH secretion and low ACTH-adrenocortical activity.

2) The fast $\alpha$ dominant MV ( $\alpha \mathrm{F}$ type) is interpreted as indicating a sympathicohypotonic state with relatively low FSH secretion and high ACTH-adrenocortical activity. (See pp. 828 839) 


\title{
Microvibration よりみた月経異常老の自律神経・ 内分泌環境に関する研究
}

\author{
九州大学医学部産科婦人科学教室 (指導 滝 一郎教授)
}

後藤哲 也

（昭和 44 年 4 月 12 日受付）

正常性周期を有する婦人の microvibration (MV) を観察分類し, 月経異常者について, 間脳下垂体 副腎皮質系および卵巣系機能，更に交感神経副腎葡質機能を内分泌学的に検索し，MV と対比した結果， slow $\alpha$ dominant $\mathrm{MV}(\alpha \mathrm{S}$ type) は交感神経緊張㐫進, FSH 優位, ACTH • 副腎皮質系低活動環境 を示し，fast $\alpha$ dominant MV ( $\alpha$ F type) は逆に交感神経緊張低下，FSH 分泌低下，ACTH・副腎皮 質系優位環境を示すものと推論された。

\section{第 I 章 緒 言}

1946年, Rohracher により温血動物の体表面に微細な振動が生理的に存在するととが報告され), minor tremor あるいは microvibration（以下 MV と略す）と呼ばれている.

その発生には脊髄反射が関係し，とくに，gamma 運動系が重要な役割を果しており，心血管系がそれに 若干の影響を及ぼしていると考えられている ${ }^{2) 3)}$ ままた，間脳とくに視床下部の活動性により影響を受け， 自律神経機能と密接な関連を有するてとが判明しているが3)，視床下部にその一次中枢を持つている内分泌 機能との関連について, 内分泌疾患を対象とした研究報告はまだない.

正常性周期を有する婦人の MV を観察分類し，月経異常者について，間脳下垂体副腎皮質系わよび卵巣 系機能, 更に交感神経副腎髄質機能を内分泌学的に検索し, MV と対比してみることは, 自律神経・内分泌 環境を視床下部レベルで解析し得る可能性を含んで, 極めて興味深い。

\section{第 II 章 研 究 方 法}

\section{第 1 節 研 究 対 象}

基礎体温 basal body temperature（以下 B.B.T. と略す）の記録により確認し得た無排卵周期症および 無月経症を対象とした。

なお，B.B.T.より正常性周期を有することが確かめられた心身共に健康な婦人10例について， B.B.T. の 記録と同時に MV を測定し, 正常 MV そついての解析を行なつた.

\section{第 2 節 $M V$ 測定法}

\section{第 1 項 pick up}

MV 誘導の pick up として圧電型 pick up を用いた³). てれは重量約 $2 \mathrm{gm}$., 直径 $23 \mathrm{~mm}$ の平型で, 上下方向に感度を有する加速度型であり, 縦方向と横方向の感度比は 10 上となつている.

\section{第 2 項 増 幅 記 録}

MV の周波数や波形は脳波のそれに類似しているため, 通常脳波用増幅器が用いられるが本研究におい ても, pick up を脳波計に接続し増幅記録した.

\section{第 3 項 誘導部位および誘導方法}


MV は身体のどの部分に pick up を置いても誘導するととが出来るが，左拇指球より誘導する方法が最 も一般的であり，本研究においても左拇指球にセロテープを用いて pick up を固定し MV を誘導記録し た。 その際, 被検者は背卧位とし, 両腕を体軸に平行に伸展し, 前腕を軽く外転させて全身の力を抜かせ, 腕の下には柔かいクッションを敷き疲れないようにした。使用した部屋は室温がほぼ $25^{\circ} \mathrm{C}$ にントロールさ れた防点の脳波室で，MVは笳の状態の僅かな変化によつても影響を受け易いため，上記誘導条件はできる だけ一定に保つようにした。

なお，記録時間は15分間とした。

\section{第 4 項 周 波 数 分 析}

脳波用周波数分析装置を用いてMVを5.5〜 7.5cps. $(\theta), 7.5 \sim 8.5 \mathrm{cps} .\left(\alpha_{1}\right), 8.5 \sim 9.5 \mathrm{cps} .\left(\alpha_{2}\right), 9.5 \sim 10.5$ cps. $\left(\alpha_{3}\right), 10.5 \sim 13 \mathrm{cps} .\left(\alpha_{4}\right)$ および $13 \sim 20 \mathrm{cps}$. $(\beta)$ の 6 率域にわけて MV を観察した（Fig. 1).

なお各帯域の出現率 (energy \%) は MV 記録開 始後10分頃の充分落着いた pattern につき次式によ つて計算した。

$\mathrm{E}^{\prime} \theta ; \%=\frac{\mathrm{A}(\theta)^{2}}{\mathrm{~A}(\theta)^{2}+\mathrm{A}\left(\alpha_{1}\right)^{2}+\cdots \cdots \cdots+\mathrm{A}(\beta)^{2}} \times 100$ $\mathrm{E}(\theta): \theta$ 波の energy

Fig. 1. Analysis of MV The vertical deflections indicate the integrated pattern of each frequency band

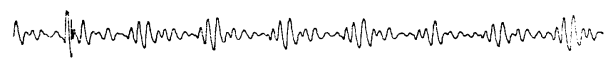

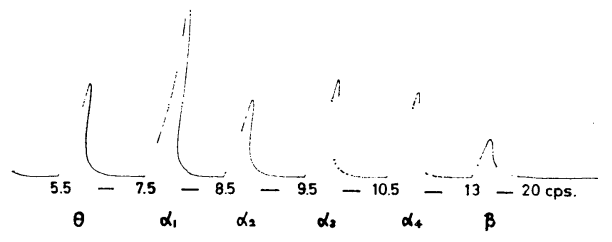
$\mathrm{A}(\theta), \mathrm{A}\left(\alpha_{1}\right), \cdots \cdots \mathrm{A}(\beta):$ 特定の 10 秒間における $\theta, \alpha_{1}, \cdots \cdots \beta$ の積分值

\section{第 3 節 間脳下垂体副腎皮質機能検查}

第 1 項 尿中 17-hydroxycorticosteroids（以下 17-OHCS と略す）および尿中 17-ketosteroids（以 下 17-KS と略す) の測定

尿中 17-OHCS は神戸川 ${ }^{4)}$ 準じて測定した。また，尿中 17-KS は Antunesによる formalin addition method を用いた Drekter 変法 ${ }^{5) 6}$ とより，Zimmermann 反応で比色定量した。

\section{第 2 項 rapid ACTH test}

副腎皮質の予備能をみるために行なつた。

Moncloa らの方法 ${ }^{7}$ に従い，午前 9 時〜10時の閻に时静脈より約 $5 \sim 6 \mathrm{cc}$ の静脈血をヘパリンでぬらした 注射器で採血, 直ちに合成24アミノ酸 ACTH (Synacthen, GIBA) $0.25 \mathrm{mg}$. を 5 ccの生理食塩水に溶かし て1 分以内で静注，正確に60分後再び肘静脈より阁様に採血し， plasma free 11-hydroxycorticoids (以下 plasma free 11-OHCS と略す) 濃度を Mattingly の方法 ${ }^{8}$ に準じて測定した。判定は60分後における plasma free 11-OHCS 值の前值よりの増加量で表わした.

\section{第 3 項 Vasopressin test}

Gwinup の方法 ${ }^{9}$ に従い，中枢における AGTH 分泌の予俑能をみるために行なつた。すなわち午後 0 時 より 1 時の間に, ヘパリンでぬらした注射器で $5 \sim 6 c c$ の静脈吕を採血, 直ちに lysine-8-vasopressin (L8-Vasopressin, Sandoz) 10 pressor units を筋注し, 筋注後正確に60分後再び同様に採血し, plasma free 11-OHCS を測定した. L-8-Vasopressin 筋注による副腎皮礩の最大反応は予備実験ですべて 60 分後にみら れ，判定は60分後における plasma free 11-OHCS 值の前値よりの増加量で表わした.

第 4 項 SU-4835 test $^{10)}$

SU-4885 (Metopirone, GIBA) $3.0 \mathrm{gm}$. を 4 回に分服させ，中枢における ACTH 分泌の予備能を尿中 17-OHCS を指標として検索した。判定は Metopirone 服用中あるいは服用後における尿中 17-OHCS 值 の前值よりの最大増加量で表わした。

\section{第 4 節 間脳下垂体卵宩機能検査}

第 1 項 尿中 estrogen の測定 
Fig. 2. Extraction procedure of urinary gonadotropin

24 hrs. urine

-adjust it to $\mathrm{pH} 4.0$ with gracial acetic acid

-centrifuge and remove the precipitate

Adsorption on kaolin : add $10 \mathrm{gm}$. kaolin per liter of urine and stir $10 \mathrm{~min}$.

- put it in refrigerator overnight centrifuge and wash the precipitate with distilled water (pH 4.0-5.0 with gracial acetic
acid) 2 or 3 times

Elution : add 1-N $\mathrm{NH}_{4} \mathrm{OH} 5$ volumes of the kaolin, stir and elute the activity twice

- centrifuge and adjust the combined elute to $\mathrm{pH} 5.5$ with gracial acetic acid

- centrifuge and add 2 volumes of acetone to the supernate

- put it in refrigerator overnight

Centrifuge and collect the precipitate

Fraction A (crude gonadotropin)

Extraction : add 5-10 ml. of $10 \% \mathrm{CH}_{3} \mathrm{COONH}_{4}$ in $70 \%$ ethanol, stir and extract twice

- centrifuge and add 2 volumes of $10 \% \mathrm{CH}_{3} \mathrm{COONH}_{4}$ in $100 \%$ ethanol to the combined extract

- put it in refrigerator overnight

centrifuge and wash the precipitate with ethanol and ether

- dry in desiccator

Fraction B

岡村・永川 ${ }^{11)}$ に準じて測定した.

第 2 項 尿中 follicle stimulating hormone（以下 FSH と略す）の測定

Kaolin 吸着法 ${ }^{12 !}$ 亿基く松島の変法 ${ }^{13)}$ に準じて得られた crude gonadotropin を Albert が gonadotropin 精製に導入した方法 ${ }^{14}$ )を用いて抽出精製し (Fig. 2), 楠田・福嶋の bioassay system ${ }^{15}$ そより，2+2 design

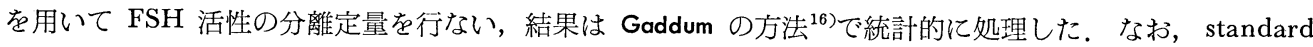
には National Institute of Health, U.S.A.より供された NIH-FSH-S 2 を用いた。

\section{第 5 節 交感神経副腎髄質機能検査}

石井・松本らの変法 ${ }^{17)}$ そり尿中 catecholamine を測定した.

なお以上のホルモン測定および負荷テストと MV 測定の期日的なズレは，各負荷テストの間隔を充分と りなお，原則として10日以内にとどめた。

\section{第而章 実 験 成 績}

\section{第 1 節 正常性周期を有する婦人の MV}

正常性周期を有する19才から 27 才の心身共に健康な婦人 10 例について, 1 周期 1 〜2回, 計 19 周期 82 回 の MV 測定を行なつた結果につき検討した。

\section{第 1 項 $\theta, \beta$ 波出現率の正常範囲}

$\theta$ 波の出現率は $\mathrm{E}(\theta)=5.48 \pm 0.366$ (mean 上standard error, 以下同じ) \%, $\beta$ 波の出現率は $\mathrm{E}(\beta)=15.13$ $\pm 1.280 \%$ であり， mean \pm 2 S.D. (standard deviation) 以内を正常範囲と考えると $\mathrm{E}(\theta) \leqq 12.11 \%, \mathrm{E}(\beta)$ $\leqq 38.31 \%$ であつた.

第 2 項 MV pattern の分類 (Table 1) 
Table 1. Classification of MV pattern

1. $\theta$-type : $\theta(5.5-7.5 \mathrm{cps}$. $)$ is most dominant. $\mathrm{E}(\beta) \geqq 40 \%: \theta-\beta$

2. $\alpha$ S-type : slow $\alpha$ (7.5-9.5cps.) is most dominant.

a) $\alpha \mathrm{s} \quad: \mathrm{E}(\theta)<15 \%, \mathrm{E}(\beta)<40 \%$

b) $\alpha \mathrm{s}-\theta: \mathrm{E}(\theta) \geqq 15 \%$

c) $\alpha \mathrm{s}-\beta \quad \mathrm{E}(\beta) \geqq 40 \%$

3. $\alpha$ F-type : fast $\alpha(9.5-13 \mathrm{cps}$.) is most dominant.

a) $\alpha \mathrm{f}: \mathrm{E}(\theta)<15 \%, \mathrm{E}(\beta)<40 \%$

b) $\alpha \mathrm{f}-\theta: \mathrm{E}(\theta) \geqq 15 \%$

c) $\alpha \mathrm{f}-\beta \quad \mathrm{E}(\beta) \geqq 40 \%$

4. $\beta$-type : $\beta(13-20 \mathrm{cps}$.) is most dominant. $\mathrm{E}(\theta) \geqq 15 \%: \beta-\theta$

5. L-type : labile type

上記正常範囲を考虑して Table 1 の如く MV pattern を分類した. なお， L (labile) type とは安静臥 床 10〜15 分を経ても pattern が安定せず動摇を示す ものであるが，乙のように分類すると， $\alpha \mathrm{s}$ 及び $\alpha \mathrm{f} の$ 2 型が正常 pattern と考えられる.

正常婦人における MV 各 type の分布を示すと Fig. 3 の如くであり， $\alpha \mathrm{s} ， \alpha \mathrm{f}$ 両 type が同数に出現し た。 なお，翼常 pattern としては $\alpha \mathrm{f}-\theta$ 及び $\alpha \mathrm{f}-\beta$ type が备 1 回， $\beta$ type が 2 回出現したが，その他の異 常 pattern は全く認められなかつた.

第 3 項 MV pattern 亡 $\mathbf{E}(\boldsymbol{\beta}) / \mathbf{E}(\boldsymbol{\theta})$ 比

$\alpha \mathrm{s}$ type と $\alpha \mathrm{f}$ type について $\mathrm{E}(\beta) / \mathrm{E}(\theta)$ 比をみると, 各々 $1.77 \pm 0.209(\mathrm{~N}=39)$ および $5.42 \pm 0.703$ $(\mathrm{N}=39)$ であり，その差は有意であつた（p<0.01）。すすわち $\alpha$ s type においては $\theta$ 成分が比較的多く, $\alpha \mathrm{f}$ type においては $\beta$ 成分が多いわけであるが，乙のととより，正常 MV においては slow $\alpha$ と, fast $\alpha$ と $\beta$ はほぼ一致した変動を示す傾向を有するものと思われた。

第 4 項 正常性周期における MV pattern および $\mathbf{E}(\beta) / \mathbf{E}(\theta)$ 比の変動

Fig. 4 亿示す如くである，なお，図中排卵期は，B.B.T. そて排卵日と思われる日を排卵 0 日とし，その 前後を排卵 -1日および＋1日として 3 区分したものであるが，排卵前期〜排卵日，および月経前期の両区 分の MV pattern の構成は，排卵 +1 日〜排卵後期のそれとは明らかに異り（p<0.05), 前 2 者において は $\alpha$ s type の出現が多く, 後者においては $\alpha$ fype の出現が多いてとを認めた. また月経期から月経後期 にかけては, $\alpha \mathrm{s}, \alpha \mathrm{f}$ 両 type の出現はほぼ同じであつた.

さらに $\mathrm{E}(\beta) / \mathrm{E}(\theta)$ 比についてみると，月経後期から排卵日，および月経前期においては $\theta$ 成分が比較的 多く, 排卵 +1 日から排卵後期にかけては逆に $\beta$ 成分が急増するのが認められた.

\section{第 2 節 月経異常者の MV}

月経異常者を病型別に分類し，その MV pattern の構成を正常対照と比較すると Table 2 の如くであ つた. $\alpha \mathrm{S}$ type と $\alpha \mathrm{F}$ type の出現は, 無月経 I 度において正常対照群に比し $\alpha \mathrm{F}$ dominant の傾向を認め たが $(\mathrm{p}<0.1)$ ，他の群ではいづれも正常対照と大差はなかつた。

異常 MV の出現率については，95\%信頼区間 ${ }^{18)}$ からもほぼ明らかであるが，無月経II度においてその出 現率は対照に比し有意に高く（ $\mathrm{p}<0.005)$, 月経異常者全体としでみた場合もその出現率は有意に高かつたが $(\mathrm{P}<0.05)$, 無排卵周期症や無月経 I 度では差を認めなかつた。また，無月経 II 度と無排卵周期症および無 
Fig. 4. The variation of $\mathrm{MV}$ pattern and $\mathrm{E}(\beta) / \mathrm{E}(\theta)$ ratio during normal menstrual cycle (10 cases, 19 cycles, 82 records)

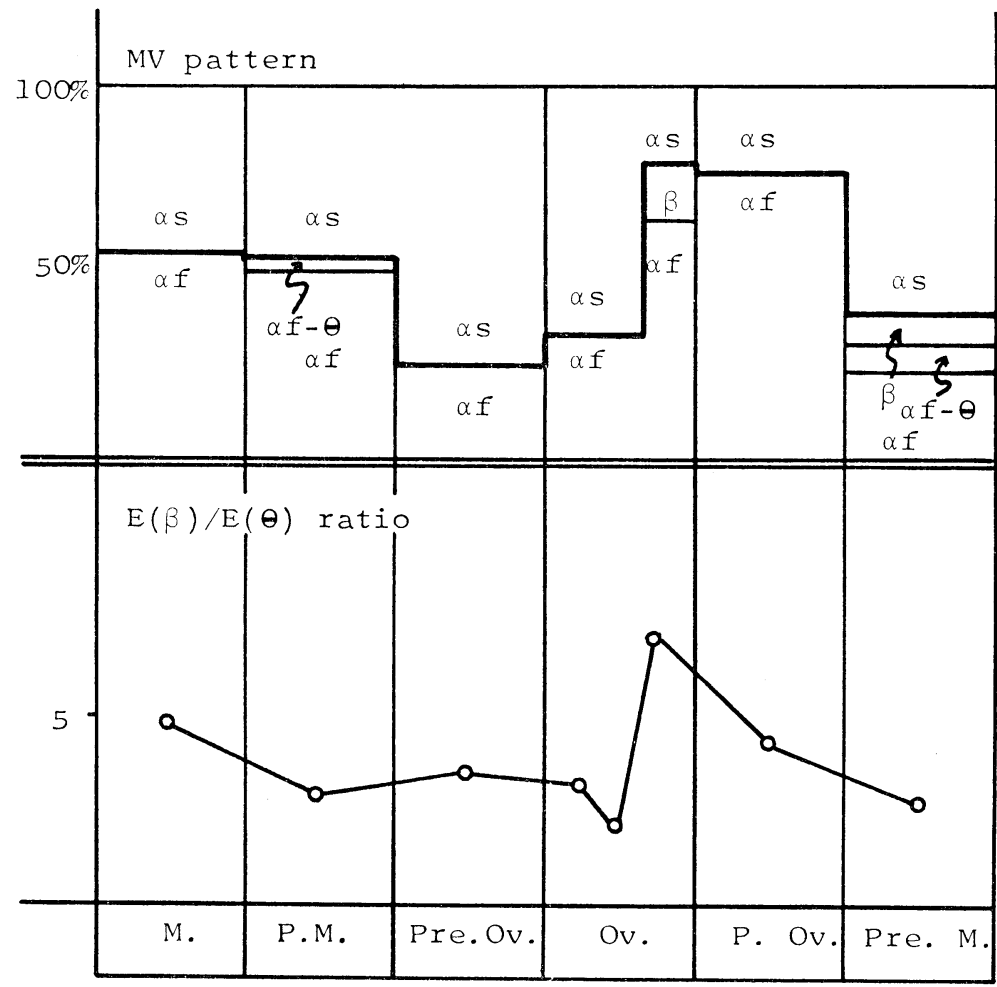

M. : menstrual phase,

P.M. : postmenstrual phase,

Pre.Ov. : preovulatory phase,

Ov. : ovulatory phase $(-1,0,+1$ day $)$,

P. Ov. : postovulatory phase,

Pre. M. : premenstrual phase.

Table 2. MV of patients with menstrual disorder

\begin{tabular}{|c|c|c|c|c|c|c|c|c|c|c|c|}
\hline \multirow{2}{*}{ disorders $M V$} & \multirow{2}{*}{$\theta$} & \multicolumn{3}{|c|}{$\alpha \mathrm{S}$} & \multicolumn{3}{|c|}{$\alpha \mathrm{F}$} & \multirow[b]{2}{*}{$\beta$} & \multirow{2}{*}{$\mathrm{L}$} & \multicolumn{2}{|c|}{ abnormal MV } \\
\hline & & $\alpha \mathrm{s}-\theta$ & $\alpha \mathrm{s}$ & $\alpha \mathrm{s}-\beta$ & $\alpha \mathrm{f}-\theta$ & $\alpha \mathrm{f}$ & $\mid \alpha \mathrm{f}-\beta$ & & & $\begin{array}{l}\text { frequency of } \\
\text { occurrence }\end{array}$ & $\begin{array}{l}95 \% \text { fiducial } \\
\text { interval }\end{array}$ \\
\hline anovulatory cycle & 0 & 0 & 4 & 0 & 1 & 6 & 0 & 0 & 0 & $1 / 11(9.1 \%)$ & $0.1-42.0 \%$ \\
\hline amenorrhea I G. & 0 & 1 & 6 & 0 & 1 & 15 & 1 & 0 & 0 & $3 / 24 \quad(12.5 \%)$ & $2.6-32.7 \%$ \\
\hline amenorrhea II G. & 0 & 1 & 9 & 0 & 2 & 6 & 0 & 0 & 3 & $6 / 21 \quad(28.6 \%)$ & $11.5^{-52.5 \%}$ \\
\hline total & 0 & 2 & 19 & 0 & 4 & 27 & 1 & 0 & 3 & $10 / 56(17.7 \%)$ & $8.9-30.2 \%$ \\
\hline control & 0 & 0 & 39 & 0 & 1 & 39 & 1 & 2 & 0 & $4 / 82(4.9 \%)$ & $1.4-12.5 \%$ \\
\hline
\end{tabular}

月経 I 度の間にも差を認めなかつた。

\section{第3 節 $M V$ 之間脳下垂体副腎皮質機能}

第 1 項 MV と 尿中 17-OHCS 
Fig. 5. MV and diencephalohypophysis-adrenocortical function
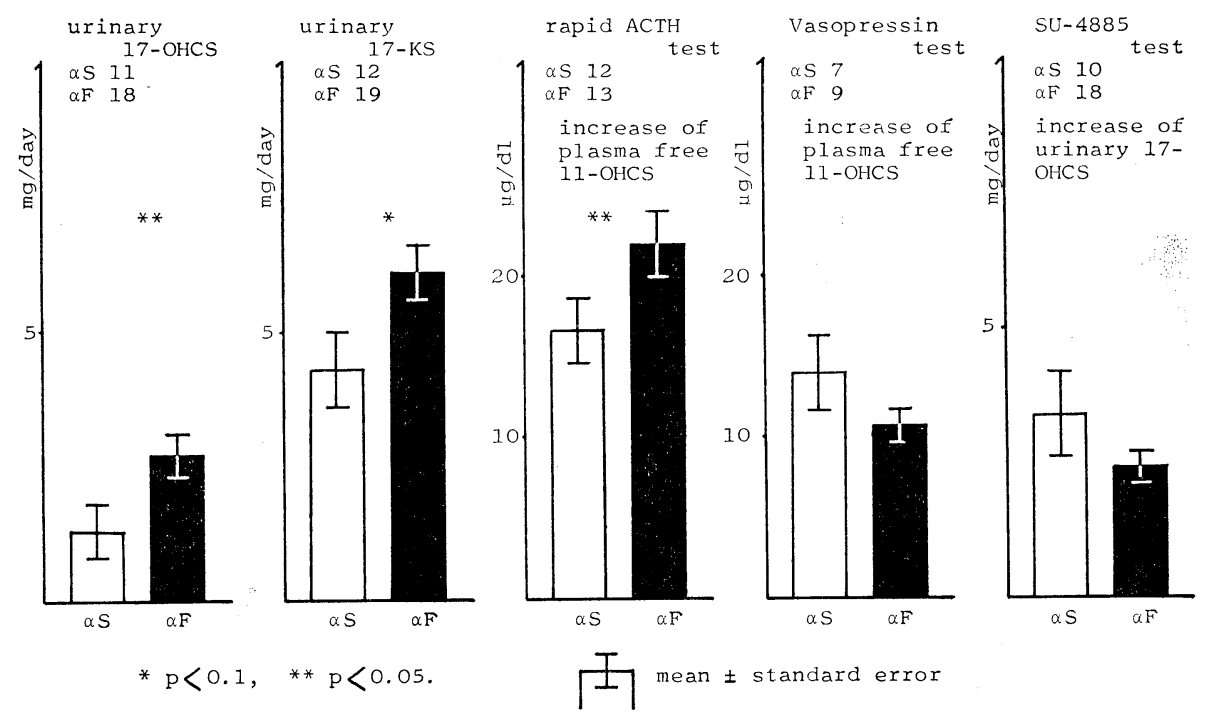

無排卵周期症 7 例，無月経 I 度 12 例，無月経 II 度 10 例の計 29 例， MV 分類では例 $\alpha \mathrm{S}$ type 11 例 $(\alpha \mathrm{s}$ : 10 例, $\alpha \mathrm{s}-\theta: 1$ 例), $\alpha \mathrm{F}$ type 18 例 ( $\alpha \mathrm{f}: 16$ 例, $\alpha \mathrm{f}-\theta: 2$ 例) につき検討した.

結果は Fig. 5 亿示す如くで, $\alpha \mathrm{S}, \alpha \mathrm{F}$ 両 type 亿おける平均值はそれぞれ $1.27 \pm 0.468 \mathrm{mg}$./day, $2.68 \pm 0.447$ $\mathrm{mg} . / \mathrm{day}$ であり, $\alpha \mathrm{F}$ type で高值を示した $(\mathrm{p}<0.05)$.

\section{第 2 項 $\mathrm{MV}$ 亡 尿中 $17-\mathrm{KS}$}

無排卵周期症 7 例, 無月経 I 度 14 例, 無月経 II 度 10 例の計 31 例, MV 分類では $\alpha \mathrm{S}$ type 12 例 $(\alpha \mathrm{s}$ ： 11 例, $\alpha \mathrm{s}-\theta: 1$ 例), $\alpha \mathrm{F}$ type 19 例（ $\alpha \mathrm{f}: 17$ 例， $\alpha \mathrm{f}-\theta: 2$ 例）につき検討した.

結果は Fig. 5 亿示す如くで, $\alpha \mathrm{S}, \alpha \mathrm{F}$ 両 type における平均值はそれぞれ $4.32 \pm 0.748 \mathrm{mg}$. $/ \mathrm{day}, 6.09 \pm$ $0.546 \mathrm{mg} . / \mathrm{day}$ であり, $\alpha \mathrm{F}$ type で高值を示した $(\mathrm{p}<0.1)$.

\section{第3 項 MV と rapid ACTH test}

無排卵周期症 3 例，無月経 I 度 12 例，無月経 II度 10 例の計 25 例， MV 分類では $\alpha \mathrm{S}$ type 12 例 ( $\alpha \mathrm{s}$ ： 11 例, $\alpha \mathrm{s}-\theta: 1$ 例), $\alpha \mathrm{F}$ type 13 例 ( $\alpha \mathrm{f}: 12$ 例, $\alpha \mathrm{f}-\theta: 1$ 例) 亿つき検討した.

結果は Fig. 5 亿示す如くで, $\alpha \mathrm{S}, \alpha \mathrm{F}$ 両 type そおける ACTH 静注 60 分後の plasma free 11-OHCS 增加量平均值はそれぞれ $16.8 \pm 2.14 \mu \mathrm{g} . / \mathrm{dl} ., 22.1 \pm 1.87 \mu \mathrm{g} . / \mathrm{d} 1$. であり， $\alpha \mathrm{F}$ type で高值を示した $(\mathrm{p}<0.05)$.

第 4 項 MV と Vasopressin test

無排卵周期症 3 例, 無月経 $\mathrm{I}$ 度 7 例, 無月経 II 度 6 例の計 16 例, $\mathrm{MV}$ 分類では $\alpha \mathrm{S}$ type 7 例（すべて $\alpha \mathrm{s}), \alpha \mathrm{F}$ type 9 例 $(\alpha \mathrm{f}: 7$ 例, $\alpha \mathrm{f}-\theta: 2$ 例 $)$ につき検討した.

結果は Fig. 5 亿示す如くで, $\alpha \mathrm{S}, \alpha \mathrm{F}$ 両 type そおけるVasopressin 筋注60分後の plasma free 11-OHCS 増加量平均值はそれぞれ $13.5 \pm 2.47 \mu \mathrm{g} . / \mathrm{dl} ., 10.5 \pm 1.08 \mu \mathrm{g} . / \mathrm{dl}$. であり， $\alpha \mathrm{F}$ type で若干低值を示したが，両 type の間に有意差は認められなかつた。

\section{第 5 項 MV ¿ SU-4885 test}

無排卵周期症 6 例, 無月経 I 度 12 例, 無月経 II 度 10 例の計 28 例, MV 分類では $\alpha \mathrm{S}$ type 10 例 $(\alpha \mathrm{s}: 9$ 例, $\alpha \mathrm{s}-\theta: 1$ 例), $\alpha \mathrm{F}$ type 18 例 ( $\alpha \mathrm{f}: 15$ 例, $\alpha \mathrm{f}-\theta: 3$ 例) 飞つき検討した.

結果は Fig. 5 亿示す如くで, $\alpha \mathrm{S}, \alpha \mathrm{F}$ 両 type における尿中 17-OHCS 最大増加量平均值はそれぞれ $3.42 \pm$ $0.827 \mathrm{mg}$./day, $2.39 \pm 0.300 \mathrm{mg}$./day であり， $\alpha \mathrm{F}$ type で若干低值を示したが両者の間に有意差は認められな 
Fig. 6. MV and diencephalohypophysis-ovarian function

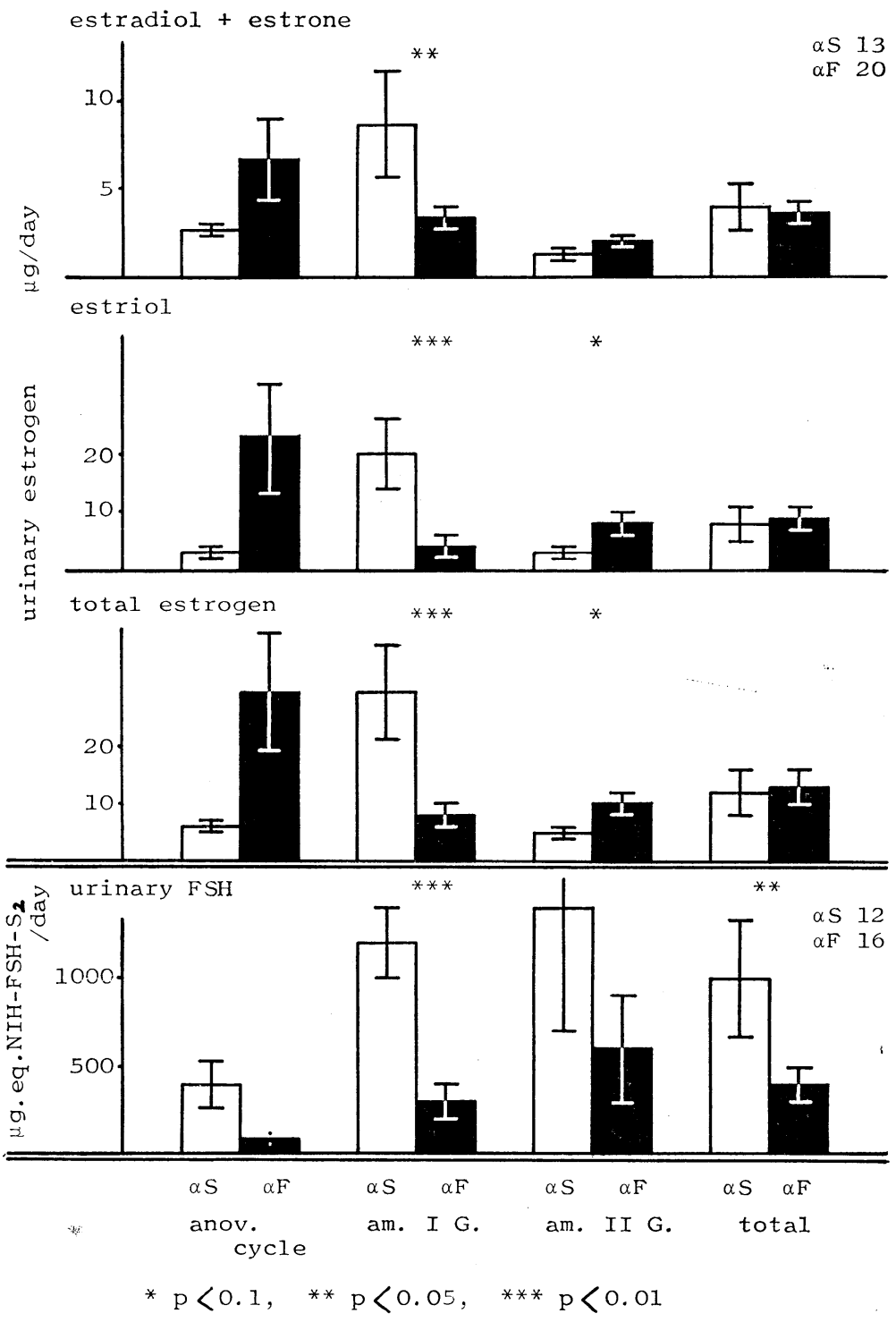

かつた。

\section{第 4 節 MV 亡間脳下垂体卵宩機能}

第 1 項 MV と尿中 estrogen

無排卵周期症 7 例, 無月経 I 度 14例, 無月経 II 度 12 例の計 33 例, $\mathrm{MV}$ 分類では $\alpha \mathrm{S}$ type 13 例 $(\alpha \mathrm{s}: 12$ 例, $\alpha \mathrm{s}-\theta: 1$ 例), $\alpha \mathrm{F}$ type 20 例 ( $\alpha \mathrm{f}: 18$ 例, $\alpha \mathrm{f}-\theta: 2$ 例) につき検討した.

結果は Fig. 6 に示す如くで, estradiol + estrone, estriol, total estrogen ともに同様の傾向を示し, 無排 卵周期症, 無月経 I度においては $\alpha \mathrm{F}$ type が高值を示したが, 無月経 I 度においては逆に $\alpha \mathrm{S}$ type が高值 を示した。 
また月経異常全体としてみた場合， $\alpha \mathrm{S}, \alpha \mathrm{F}$ 両 type 間に全く差は認められなかつた.

\section{第 2 項 $\mathrm{MV}$ と尿中 FSH}

無排卵周期症 5 例，無月経 I 度 12 例，無月経 II度 11 例の計 28 例， $\mathrm{MV}$ 分類では $\alpha \mathrm{S}$ type 12 例 $(\alpha \mathrm{s}$ : 11 例, $\alpha \mathrm{s}-\theta: 1$ 例), $\alpha \mathrm{F}$ type 16 例 ( $\alpha \mathrm{f}: 14$ 例, $\alpha \mathrm{f}-\theta: 2$ 例) につき検討した.

結果は Fig. 6 亿示した如くで, 無排卵周期症, 無月経 I 度, 無月経 II 度のいずれも $\alpha \mathrm{S}$ type で高值を示 した。 また，月経異常全体としてみた場合も $\alpha \mathrm{S}$ type では $1084 \pm 350.9 \mu$ g. eq. NIH-FSH-S $/$ day, $\alpha \mathrm{F}$ type では $372 \pm 102.9 \mu \mathrm{g}$. eq. NIH-FSH-S $/$ day で，両者間には有意な差が認められた $(\mathrm{p}<0.05)$.

Fig. 7. MV and sympathetic nerve-adrenomedullar function

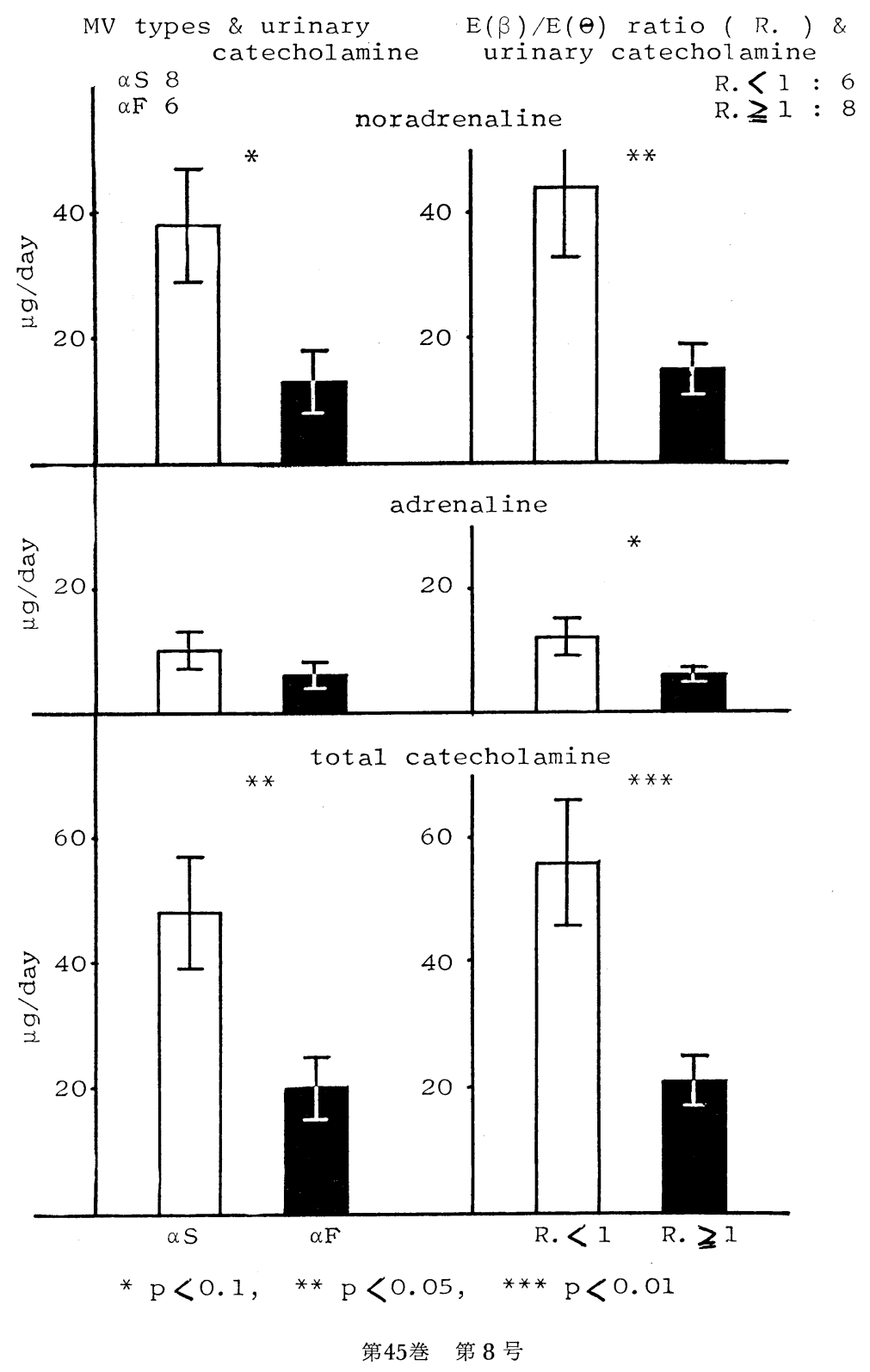




\section{第 5 節 $M V$ と交感神経副腎髄質機能}

\section{(MV pattern および $\mathbf{E}(\boldsymbol{\beta}) / \mathbf{E}(\boldsymbol{\theta})$ 比と尿中 catecholamine)}

無排卵周期症 4 例, 無月経 I 度 5 例, 無月経 II 度 5 例の計 14 例, $\mathrm{MV}$ 分類では $\alpha \mathrm{S}$ type 8 例 $(\alpha \mathrm{s}: 6$ 例, $\alpha \mathrm{s}-\theta: 2$ 例)， $\alpha \mathrm{F}$ type 6例（すべて $\alpha \mathrm{f}$ ) について検討した.

結果は Fig. 7 に示した如くで, noradrenaline, adrenaline, total catecholamine のいずれも $\alpha \mathrm{S}$ type おいて高值を示した。 また， $\mathrm{E}(\beta) / \mathrm{E}(\theta)$ 比では $\mathrm{E}(\beta) / \mathrm{E}(\theta)<1$ の群でいずれも高值を示し，MV pattern の分類におけるよりもその差は明瞭であつた。

\section{第IV章 考按}

MV と自律神経内分泌環境に関して本実験で得られた結果を一括表示すれば Table 3 の如くであり, Fig. 8 の如く 2 つの pattern に模式化出来る.

Table 3. MV \& autonomic nervous and endocrinous function

\begin{tabular}{|c|c|c|c|}
\hline & $\alpha S$ & $\alpha F$ & $P$ \\
\hline $\begin{array}{l}\text { diencephalohypophysis-adrenocortical function } \\
\text { urinary } 17-O H C S\end{array}$ & * & 4 & $P<005$ \\
\hline urinary $17-K S$ & 1 & 4 & $P<01$ \\
\hline $\begin{array}{c}\text { response of plasma free } 11-O H C S \\
\text { to rapid ACTH test }\end{array}$ & 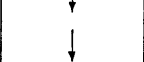 & 1 & $P<0.05$ \\
\hline $\begin{array}{c}\text { response of plasma free } 11-\text { OHCS } \\
\text { to Vasopressin test }\end{array}$ & $\nearrow$ & * & N.S.** \\
\hline $\begin{array}{r}\text { response of urinary } 17-\text { OHCS } \\
\text { to SU-4885. test }\end{array}$ & $\nearrow$ & $\searrow$ & N.S. \\
\hline $\begin{array}{l}\text { diencephalohypophysis - ovarian function } \\
\text { in normal menstrual cycle }\end{array}$ & $\begin{array}{l}\text { main type } \\
\text { of Pre. Ov. } \\
\text { Ov.O day \& } \\
\text { Pre.M. } * *\end{array}$ & $\begin{array}{l}\text { main type } \\
\text { of Ov.+1 } \\
\text { day } \sim \text { P. Ov. } \\
* *\end{array}$ & $p<0.05$ \\
\hline urinary estrogen & I or $\searrow$ & $Y$ & N.S. \\
\hline urinary $F S H$ & $\uparrow$ & $\downarrow$ & $P<0.05$ \\
\hline $\begin{array}{l}\text { sympathetic nerve - adrenomedullar function } \\
\text { urinary catecholamine }\end{array}$ & $\uparrow$ & $\downarrow$ & $P<0.05$ \\
\hline
\end{tabular}

* 1 ,, or $1, \mathrm{X}$ : relatively high or low.

** Pre.Ov. : preovulatory phase Ov. O day : ovulatory O day,

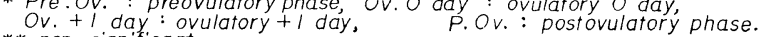

Fig. 8. MV \& autonomic nervous and endocrinous function

1. aS type :

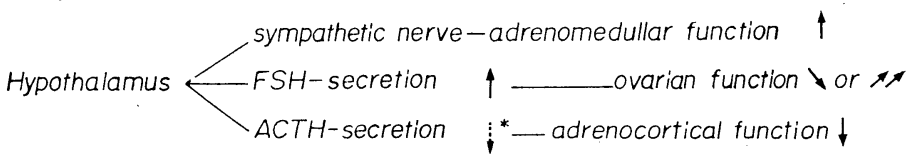

2. $\alpha$ F type :

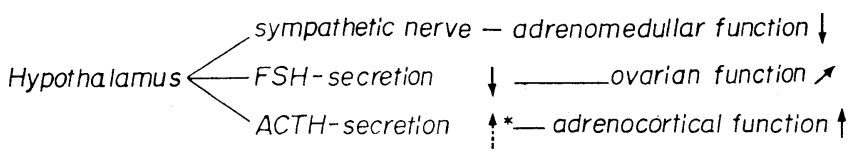

$* 4:$ : expected direction. 
すなわち副腎皮質機能については，尿中 17-OHCS および 17-KS よりその basal function を判定する と，両ホルモンともに $\alpha \mathrm{F}$ type において $\alpha \mathrm{S}$ type に比して高值を示し，前者の副腎皮質 basal function が比較的立進しているととがうかがわれ，乙れは，ひいては中枢におらる ACTH の basal secretion が立 進しているための現象であろうと推定される。 また $\alpha \mathrm{F}$ type においては, rapid ACTH test を示標とした 副腎皮質の reserve function も $\alpha \mathrm{S}$ type に比して良く，乙の事象は，極く少量の ACTH を持続点滴す ると副婜皮質の $\mathrm{ACTH}$ 亿対する反応性が元まるという報告 ${ }^{19)}$ と考え合せると， $\alpha \mathrm{F}$ type においては $\alpha \mathrm{S}$ type に比し中枢そおける ACTH の basal secretion が元まつているととが前述 17-OHCS, 17-KS 測定の 結果からと同様に推定される。

一方，中枢における AGTH の reserve を Vasopressin test, SU-4885 test でみると，副腎皮質機能が 相対的に六進し，ACTHの basal secretion が亢まつていると推定される $\alpha \mathrm{F}$ type におろてむしろ若干低

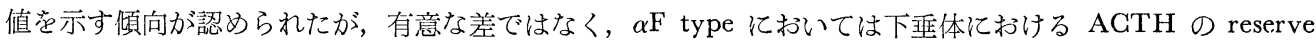
が減少しているかあるいは視床下部レベルで，血中 corticoid の減少またはVasopressin に対する感受性が 低下しているなどの可能性が考えられるが，ACTHの reserve function test の結果から，ACTH の basal secretion を推定するととは困難であろう。

次に，間脳下垂体卵宩機能については，まず正常性周期における $\mathrm{E}(\beta) / \mathrm{E}(\theta)$ 比の変動をみると，月経後 期から排卵日にかけては $\theta$ 成分が比較的多く，排卵 +1 日から排卵後期にかけては逆に $\beta$ 成分が急増するの

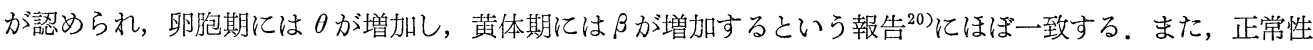
周期における MV pattern の変動をみると，排卵前期から排卵日にかけて estrogen が peak を作る時期 には $\alpha \mathrm{S}$ type が優位を示し，排卵日を境にして estrogen 活性がまだ高い排卵+1日から排卵後期にかけて は $\alpha \mathrm{F}$ type が優位となり, estrogen 活性が低下してくる月経前期には再び $\alpha \mathrm{S}$ type が優位となる. 更に, 月経異常者の尿中 estrogen 測定の結果からも無月経 I 度における如く， $\alpha \mathrm{F}$ type に比し estrogen の高值 に $\alpha$ S type が対応する場合と，逆に無排卵周期症や無月経I度にみられる如く，むしろ低值に対応する場 合が認められ, estrogen と MV pattern の間には一定の傾向は認められない. 一方尿中 FSH と MV pattern の関係には，無排卵周期症，無月経 I 度，無月経 II度のすべてに一定の傾向があり， $\alpha \mathrm{S}$ type におい ては $\alpha \mathrm{F}$ type に比し常に FSH 高值を示している.

以上の事象から，MV pattern は， estrogen 活性そのものによつて影響を受けるのではなく，それらの estrogen 活性が negative feed back あるいは positive feed back 機構を介して䏥枢特に視床下部に影響 を与え，その結果，中枢特に視床下部に生じたある種の活動状態が FSH と MV pattern の対応関係を形 成するとの可能性が示晙される。

更に，MV pattern を中心にして FSH と ACTH・副腎皮質系の関係をみると， $\alpha$ type は相対的に FSH 優位，ACTH・副腎皮質系低活動状態を， $\alpha \mathrm{F}$ type では逆に AGTH・副腎皮質系優位，FSH 分泌低下状態 を示唆し, MV は内分泌環境を副㛑皮質・性腺系から大きく 2 大别してとらえていると考えられる。

次に，交感神経副腎随質機能について，尿中 noradrenaline (NA), adrenaline (A), total catecholamine (total CA) を示標として MV pattern との関係をみると, NA, A, total CA のいずれも $\alpha \mathrm{S}$ type では $\alpha \mathrm{F}$ type に比し高值を示し， $\alpha \mathrm{S}$ type では相対的に交感神経緊张立進， $\alpha \mathrm{F}$ type では交感神経緊張低 下の状態がうかがわれる。一方， $\mathrm{E}(\beta) / \mathrm{E}(\theta)$ 比もてれら catecholamine とはよく対応し， $\mathrm{E}(\beta) / \mathrm{E}(\theta)<1$ すなわち $\theta$ 成分 $>\beta$ 成分では交感神経緊張九進, $\mathrm{E}(\beta) / \mathrm{E}(\theta) \geqq 1$ すなわち $\beta$ 成分 $\geqq \theta$ 成分では交感神経緊張 低下を示唆し, 神経薬物と MV との関係を検討した報告 ${ }^{21)}$ とおいても同様の結果が指摘されており, 交感

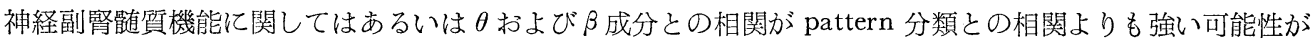
うかがわれるが，第亚章，第 1 節，第 3 項に述べた如く， $\theta$ と slow $\alpha, \beta$ f fast $\alpha$ はほぼ一致した变動を 示すため, pattern 分類でも前述の如くほぼ交感神経副腎髄質機能を反映するものと考えられる。

また，乙れらの自律神経機能と前述の内分泌環境の間とは MV を介して， $\alpha \mathrm{S}$ type $=\mathrm{FSH}$ 優位環境二交 感神経緊張光進， $\alpha \mathrm{F}$ type $=\mathrm{ACTH}$ ・副腎皮質系優位環境二交感神経緊張低下の関係が成立するものと考え 
られる。

MV の中枢性支配に関しては，すでそネコあるいは家鬼を用いる刺激実験の結果がくつか報告されて いる ${ }^{2223324) 25) 26)}$.すなわち, MV 促進領として大脳皮質運動領, 視床下部前部, 視床下部外側核, 海馬, 橋部網様体など, 抑制領としては, 内側視束前野, 腹内側核を中心とする視床下部内側部, 視床下部後部, 阴桃核, 中脳部網様体などである。

一方, 性周期における家鬼脳各部位の活動レベルについて電気生理学的な面からみると estrous stage に おいて活動レベルが上昇し， postcoital stage において活動レベルが低下する部（本論文中では仮に発情中 枢と呼ぶ）と，逆に estrous stage そおいて活動レベルが低下し， postcoital stage において活動レベルが

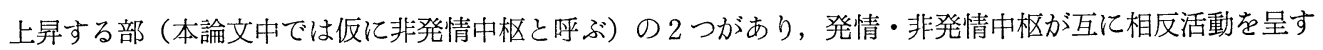
るととが報告されている ${ }^{27}$ が，発情中枢と MV 抑制領，非発情中枢と MV 促進領の間には視床下部を中 心として部位的に一致する点が多く，とくに発情中枢と MV 抑制領の一致性は高い. 更にてれらの部を自 律神経中枢との関連よりみれば MV 促進領（非発情中枢）は副交感性領域2829233031) そ，MV抑制領（発 情中枢）は交感性領域 ${ }^{28292330322}$ にほぼ一致し，MV 促進領二非発情中枢二副交感性中枢，MV 抑制領二発 情中枢二交感性中枢の関係が成立し，動物実験による MV 中枢，性中枢，自律神経中枢の関連 ${ }^{33334}$ は，今 回の研究で得られた MV pattern, 内分泌環境，自律神経環境の関連と類似性を有しており，てのような観 点よりすれば，MV は視床下部の活動性の表現であり，従つて，単に末梢，または大脳皮質など視床下部 より上位の中枢における内分班自律神経系の変化そのものをとらえるのではなく, それらの変化を主として 視床下部の活動を介してとらえている可能性が推論される.

また, 同様の観点から, 異常 MV は gamma 運動系や筋自体に異常のない限り, 視床下部に異常な負荷 がかかつているか，あるいは視床下部自体の異常を示唆するものであううと考えられる。

\section{第 V章 結論}

正常性.周期を有する婦人の MV を観察分類し，月経異常者について，間脳下垂体副腎皮質系および卵栄 系機能, 更に交感神経副腎榷質機能を内分泌学的に検索し MV と対比した結果, 次の如き結論を得た.

1) 正常 MV pattern は $\alpha \mathrm{s} ， \alpha \mathrm{f}$ の 型であつたが， $\alpha$ s type においては $\theta$ 成分が比較的多く， $\alpha \mathrm{f}$ type においては $\beta$ 成分が多い傾向が認められた。

2 ) 正常性周期に伴つて MV は変動を示した。すなわち排卵前期〜排卵日，および月経前期では $\theta$ およ び slow $\alpha$ が増加し $\alpha$ s type が優位となり，排卵+1日〜排卵後期では $\beta$ および fast $\alpha$ が著明に増加し， $\alpha \mathrm{f}$ type が優位となる傾向が認められた。

3）月経異常者においては異常 MV を呈する頻度が正常対照に比して高かつたが，とくに無月経I度に おいて著明であつた。

4) 交感神経副掔髄質系および性腺副腎皮質系機能から自律神経内分泌罢境を大別すると，MV pattern によつて $\alpha \mathrm{S}$ type と $\alpha \mathrm{F}$ type の 2 型に分類され, $\alpha \mathrm{S}$ type は交感神経緊張六進, FSH 優位, AGTH・副 腎皮質系低活動環境を， $\alpha \mathrm{F}$ type は交感神経緊張低下，FSH 分泌低下，ACTH・副婜皮質系優位環境を示 唆するものと推論された.

5）MV と自律神経内分㤅環境との関連，および MV 中枢，自律神経中枢，性中枢に関する文献的考察 から，MVが主として視床下部の活動状態を表現している可能性について考按した。

懇籃なる御指導と御校閲を賜わつた恩師溯一郎教授，今井環教授並びに古賀康八郎前教授に心から感謝の 意を捧げるとともに，終始御指導御鞭撻頂いた岡村靖講師，MV测定に関して御配虑御助言を頂いた心療内 科学教室菅野久信助教授はじめ諸先生各位, 実験に際し御配虑頂いた中央検査部永井毫爾部長, 並びに種々 御協力頂いた教室諸先生各位に厚く感謝致します.

また，尿中 17-OHCS，尿中 estrogen および尿中 catecholamine の測定に多大な援助を頂いた教室荒川 
公否博士, 永川正敏学士, 上笹貫修学士, 倉野彰比古学士に心から感謝致します.

なお本論文の一部要旨は第20回日本産科婦人科学会総会において宿題報告の一部として発表した。

\section{文献}

1) ROHRAGHER, H. : Anz. d. phil.-hist. Klasse d. Akad. d. Wiss., 18 : 230, (1946).

野久信, 稲永和豊: 脳と神経, $10: 769$, , (1958).

3）稲永和豊編: Microvibration, 第 1 版 (1966), 医学書院, 東京.

4) 神戸川 明：木之臨, $11: 191,(1963)$.

5) ANTUNES, L.N. : J. Clin. Endocrinol. and Metab., 16 : 1125, (1956).

6) DREKTER, I.J., S. PEARSON, E. BARTCZAK and T.H. McGAVACK : J. Clin. Endocrinol. and Metab., $7: 795$, (1947).

7) MONCLOA, F., I. VELEZCO and L. A. GUTIERREZ : J. Clin. Endocrinol. and Metab., 26 : 482, (1966).

8) MATtingly, D. : J. Clin. Path., $15: 374$, (1962).

9) GWINUP, G. : Lancet, $18: 572$, (1965). 10$)$ LIDDLE, G.W., D. ISLAND, E.M. LANCE and A.P. HARRIS : J. Clin. Endocrinol. and Metab., $18: 906$, (1958).

11）岡村 靖, 永川正敏：医学のあゆ み, $55: 503,(1965)$.

12) BRADBURY, J.T., E.S. BROWN and W.E.BROWN : Proc. Soc. Exp. Biol. Med., $71: 228$, (1947). 13) 松島早苗 : 木之臨, $10 ： 169$, (1962).

14) ALBERT, A., J. KOBI, J. LEIFERMAN and I. DERNER : J. Clin. Endocrinol. and Metab., $21: 1$, (1961). 15) 桶田雅彦, 福嶋恒彦: 木之臨, $14: 829$, (1966). 16) GADDUM, J.H. : Pharmacol. Rev., $5: 87$ ，(1953). 17) 石井敏武, 松本寿通, 渡辺仁夫 : 日内分泌誌, $36: 1695$, (1960). 18) SNEDECOR, G.W. (畑村又好, 奥野忠一, 津村善郎共訳)：統計的方法, 第 4 版 (1967), 4, 岩波書店, 東京. 19) NUGENT, C.A., K. EIK-NES, L.T. SAMUELS and F.H. TYLER : J. Clin. Endocrinol. and Metab., $19: 334$, (1959). 20) 上野 武: 福岡医誌, 50:4889, (1959). 21）稲永和豊, 佐藤利明 : 精神経誌, $61: 1957$, (1959). 22) SUGANO, H. and K. INANAGA : Jap. J. Physiol.,10 : 246, (1960). 23) SUGANO, H. : Jap. J. Physiol., 13: 492, (1963). 24) ITO, K. and K. TANAKA : Yonago Acta Med., $6: 29$, (1962). $24: 1057,(1961)$.

26) 井上茂夫 : 福岡医誌, $51: 1240$, (1960).

25）久原一男 : 久留米医誌, $14: 277$, (1966). $\quad 28)$ HESS, W.R. : Arch. Psychiat., $104: 548$, (1936). 27）川上正澄 : 木と臨, 脳研究, $3: 39$, (1949). 30) BAN, T. : Med. J. Osaka Univ., $15: 1$, (1964). 29) 黒津敏行 : A., T. BAN and T. KUROTSU : Med. J. Osaka Univ., $10: 327$, (1960).

31) SAKAI, H., S. FUSE, T. YOKOYAMA, H. WATANABE and T. WATANABE : Folia Psychiat. Neurol. Jap., $8: 336$, (1955). 33) 倉智敬一 : 第17回日本産科婦人科学会総会宿題報告, (1965), 東京, 34）貴家昭而：日産婦誌，12：1331，(1960). 